\title{
Aging and Social Gerontology vs Social Accounting in Developing
} Countries

Mohammad Taghi Sheykhi

Department of Social Science, Alzahra University, Tehran, Iran

Corresponding Author: Mohammad Taghi Sheykhi, Department of Social Science, Alzahra University, Tehran, Iran.

Received date: November 27, 2019; Accepted date: December 27, 2019; Published date: January 08,2020

Citation: Mohammad T Sheykhi. (2020) Aging and Social Gerontology vs Social Accounting in Developing Countries. J. Neuroscience and Neurological Surgery. 6(1); DOI:10.31579/2578-8868/105

Copyright: ( 2020 Mohammad T Sheykhi. This is an open-access article distributed under the terms of The Creative Commons Attribution License, which permits unrestricted use, distribution, and reproduction in any medium, provided the original author and source are credited.

\begin{abstract}
Though aging is a gift in general, it may be a hard time for many in developing countries in particular. Aging may be defined as the combination of biological, social and psychological processes that affect people as they grow older. The first refers to the physical body, the second refers to cultural values, norms and role expectations that change with age, and the third refers to the change in one's emotional, cognitive and mental capabilities. Science, modern technologies, improved agriculture, sanitation, medicaments, improved nutrition and many more developments have brought about aging increase and declining mortality. Social aspects of aging or social gerontology as a new phenomenon needs to be taken into account through social accounting. As rapid changes are emerging in population structure in modern times, social accountants need to study and project different emerging changes of population including aging and gerontology. While aging is affected by the quality of the society, it affects society too. Such a phenomenon is currently appearing in the developing world. Similarly, aging people find a different psychology and lifestyle contradicting their younger ages. Such a dramatic change needs more applicable inspection including geriatrics and social accounting. However, complications in elderly life is ever appearing and increasing. Method of research used in the present paper is mainly based on a qualitative approach. Various subtitles discussed in the present paper, result from aging, or influence aging phenomenon. The paper concludes that social accounting widely affects healthy aging.
\end{abstract}

\section{Objective}

The aim of the present research is to represent the role of social accounting as an umbrella including demographic, social, cultural and environmental indicators/ variables which bring about healthy state of life in developing countries. In the meantime, efficient management would be possible and attainable under the conditions of aging in any country. While the three social, cultural and environmental variables are a triangle being faced by the developing countries today, the quality and quantity of population also play an important and determining role, and shortage of which contributes to socio-economic vulnerabilities, smuggling and drug addiction among a large number of people in those countries. The aforementioned variables have also a pivotal role in accessing a healthy economic system. However, aging can be defined as the combination of biological, psychological, and social processes that affect people as they grow older [1].

Key words: aging; gerontology; modern technology; improved agriculture; social accounting

\section{Introduction}

Social accounting can play a determining role in population planning. Population growth rate has largely affected population structure in recent decades in the developing countries; a phenomenon leading to young population structure. While about $83 \%$ of the world population is residing in the developing world [2], social accounting is minimally associated with that, and that has resulted in increasing social abnormalities for those countries, leaving behind unemployment, poverty, unbridled migration, increasing deviances, increasing drug abuse etc. The current situation has caused $28 \%$ of population in the developing world remaining below 15 years of age. Such a scenario will encounter the countries of the developing world with a large bulk of unemployed youth in search of food and jobs in the years to come. However, the current situation is leading many developing countries to delayed marriages culminating in lower fertility within the youth of below 35 years of age [3]. Because of failures of social accounting, many developing countries are surprisingly facing young populations whom cannot be easily fed and employed. Appropriate actions must usually be notified through social accounting, and that includes economic and industrial investments versus those newly born. Under such circumstances many of those born in 1980s and beyond are in poverty conditions in developing world. The scenario means that there is not economic independence and hiring opportunities for such people. The present circumstances as a motivation, moves the youth towards antisocial behaviors. Though the family institution in some countries like Iran tries to support such young unemployed youth, yet they are pulled toward drug addiction.Therefore, to modify the existing situation, and control its continuity for the years to come, population growth rate must be checked, and a coordination between population growth rate and creation of job Opportunities need to be maintained. If that is not 
practiced, the youth should expect further deviations in the future. According to a socio-economic and demographic view, for every $1 \%$ of population growth, there should be $4 \%$ economic growth. Such a balance helps in not having unemployment and other dilemmas [4]. Though some developing countries have had declining population growth rates in recent years, yet the volume of young population has remained the same, and even some added to it (15+) every year. These youth potentially vulnerable, seriously need social accounting to be less jeopardizing the economy. However, an increasing number of the Third World countries are facing such a scenario. Hence, backgrounds for smuggling, human trafficking and the like are hereby set. Thus, to reach a healthy economy, the aforementioned destructive factors must be controlled, and eliminated. It must also be notified that the culture of drug deals could not be rooted out overnight. Sociologically speaking, social accounting based on the current parameters would be a turning point to reach a healthy aging with food accessibility. It is worth mentioning that along with the population policies, minding gerontology, and other cultural, social and environmental policies should be considered. Such a strategy could eventually help in attaining a healthy aging to operate. However, the idea of separation of older people from active roles in society is somehow normal and appropriate, and benefits both society and older individuals [5]. Though for most of human history the average life expectancy at birth was less 20 years because of increasing death rate in infancy and early childhood, it increased to 47 in the United States for those born in 1900, and today being 79 years [6]. New, while a baby born in Japan has a life expectancy of 84 years, the one born in Sierra Leone has a life expectancy of 46 years [7].

\section{Method of Research}

Methodology used in the present abridged article is of qualitative type. In that, various paradigms have been used for fact finding. The method applied in the present study, searched the needs in their natural settings. In fact finding for the research, the researcher engaged in a careful collection of data in a thoughtful manner, and what was in need and relevant, was analyzed. The documentary research applied for data collection includes printed and written materials which were widely regarded. The research being a qualitative library type, in that, the researcher had to refer to relevant and related sources; such as books, journals and statistical resources in a thorough way to access the needful information. As a naturalistic inquiry, the researcher could almost reach an in-depth understanding of some social phenomena which could help other social researchers and thinkers in the future as well.

\section{Sustenance of Healthy Aging}

Sustaining a healthy aging is only possible if housing, food, household budget and education are provided. Under such an atmosphere social management could suitably be fulfilled [8]. This is also worth mentioning that the developed countries also reach economic health through variables such as safety, discipline and social accounting.

The system of healthy aging could only be applicable under the conditions/standards of enough food and housing for all classes of people [9]. To attain the pre-planned objectives, enough investment in terms of place and time need to be applied. Many of the developing countries of the world have put into practice the necessary infrastructural indices so that they could reach the status of a healthy aging.

Atchley's theory illustrates that individuals in later life make adaptions, to enable them to gain a sense of continuity between the past and the present, and the theory implies that, this sense of somiruity helps to contribute to well-being in later life [10].

\section{Healthy Economy vs Development}

Social, environmental and cultural factors all have an effective impact on a healthy economy, an integration of all could lead to a healthy society. Similarly, healthy economy could be counted as a guardian of development in general. Hence, economic plans, and further economic growth, and also a condition in which social capital is crytstallized, each as agents of healthy economy, play role. In the meantime, creation of a safe environment will be attainable in a society, through the preservation of health in a society [11]. Similarly, accessing appropriate cultural backgrounds, or in other words, reformation of cultural and artistic structure in a society plays as the guardian of health system.

\begin{tabular}{|c|c|c|c|}
\hline \multirow{4}{*}{ Asian Continent } \\
\hline \multirow{2}{*}{ Country /Region } & \multicolumn{3}{|c|}{ Percent $\mathbf{6 5 +}$} \\
\cline { 2 - 4 } & $\mathbf{1 9 9 5}$ & $\mathbf{2 0 0 5}$ & $\mathbf{2 0 1 5}$ \\
\hline Japan & 14 & 20 & 14 \\
\hline Korea, South & 5 & 9 & 13 \\
\hline Taiwan & 7 & 9 & 12 \\
\hline Singapore & 7 & 8 & 11 \\
\hline Thailand & 4 & 7 & 11 \\
\hline Armenia & 7 & 11 & 10 \\
\hline China & 6 & 8 & 10 \\
\hline Korea, North & 4 & 8 & 85 \\
\hline Sri Lanka & 4 & 8 & 8 \\
\hline Turkey & 4 & 6 & 8 \\
\hline Iran & 4 & 6 & 7 \\
\hline Viet Nam & 5 & 4 & 7 \\
\hline Lebanon & 5 & 7 & 6 \\
\hline Azerbaijan & 5 & 6 & 6 \\
\hline India & 3 & 7 & 6 \\
\hline Nepal & 3 & 2 & 6 \\
\hline Indonesia & 4 & 4 & 5 \\
\hline Pakistan & 3 & 5 & 4 \\
\hline Iraq & 3 & 3 & 3 \\
\hline Jordan & 3 & 3 & 3 \\
\hline Saudi Arabia & 2 & 3 & 3 \\
\hline Conpan
\end{tabular}

Table 1: Comparative Aging Indicators of Selected Asian Countries in Three Periods (\%)

Source(s): World Population Data Sheet(s) 1995, 2005 and 2015.

\section{Age}

Men and women's life expectancy at birth is the highest in Japan (82 years for males, and 88 for females), and the lowest has been identified in Central African Republic (50 years for males, and 54 years for females). Various social, economic, technological and environmental infrastructures have part in such a great change in life expectancy in different parts of the world. African countries are also home to some of the world's youngest populations: those ages 15 or below, including Niger (50 percent), and Somalia (47 percent). In contrast, 27 percent of India's population is age 15 or below. Similarly, China's young population is at

18 percent as identified, and that of the United States is 19 percent. Aging populations of Asia and Europe are more as compared with other parts of the world. Such an indicator is 28 percent in Japan, 12 percent in China and 6 percent in India [12].

\section{Vulnerability of Environment}

Increasing number of urban areas in Africa, Asia and Latin America, as 
a result of their rapid population growth, poor and weak social accounting, and their deteriorating socio- economic conditions, are encountering increasing vulnerabilities. These countries have been facing extensive migrations. Such interactions have had social, economic and cultural impacts on these societies including destructive, negative environmental and social pollution, in addition to food shortage. As compared with developed societies, they are prone to a large number of vulnerabilities. The objective outcome of which has influenced different social groups of people in various aspects. Therefore, social accounting of environment will bridge the societies to social health. Such countries are constantly facing migrants to cities who encounter shortage of necessary goods and services food. Therefore, applied sociology through social accounting must be used to study the present and future generations with a focus on their needs [13].

\section{Low Fertility vs Aging}

Factors influencing low fertility rate, eventually influence aging trend with special reference to the developing countries as a new experience. They may be categorized as follows:

1. Motivational Factors--While previously there used to be a strong motivation for procreating more children, currently in most of the developed as well as the developing countries, the motivational factors are in favor of low fertility, desire for small family, availability of means of birth control technology etc.

2. Economic Factors--These include industrialization and higher standard of living. Industrialization has compelled so many males to stay in urban areas away from their females resulting in lower birth rate. Such a phenomenon has appreciably helped life expectancy to be increasing: leading to more aging people.

3. Social Factors--Social factors are closely linked with the economic factors. They include urban society with all its newly emerging standards and values, individualism and social change. Almost all the characteristics of modern societies are in favor of low fertility especially in urban areas [14].

\section{Conclusion}

Social accounting challenges conventional accounting, and is designed to support and facilitate the pursuit a country's objectives. Such objectives can be manifold, but can typically be described in terms of social and environmental desirability and sustainability, food accessibility etc. [15]. Similarly, social accounting could highly affect healthy aging and better gerontological conditions, of the increasing Aging People with special reference to the developing countries. Sociology is very much related with demography from which aging is derived. Sociological studies widely deal with population statistics. Sociological studies deal with analytical interpretation of population dynamics and composition. At present, sociologists are highly responsible to present a clear and touchable perspective of societies under the influence of rapid population change with a focus on increasing aging people as far as their health, income, nursing, security, and their many more needs are concerned. The scientific nature of aging as a new phenomenon is at present a responsibility of sociologists. Similarly, the prediction of the future demographic evolution and its probable consequences as a new agenda attracts sociological analysis and interpretation. However, population size, organization and distribution are known as aspects of social gerontology needing urther analysis. It must be noted that worldwide, and especially in developing world, aging is continuing paralleled with poverty: a phenomenon emerging as a great

Challenge / concern for an increasing number of individuals.

\section{References}

1. Abeles, R. P., and M. W. Riley, (1987), "Longevity, Social Structure, and Cognitive Aging". In C. Schooler and Social Structure Over the Life Course. Norwood, NJ: Albex.

2. Atchley, R.C. (2000) Social Forces and Aging: An Introduction to Social Gerontology, 9th ed. Belmont, CA: Wadsworth.

3. Bowling, Ann., (2005). Ageing Well: Quality of Life in Old Age, Open University Press, ISBN 0335215092.

4. Centers for Disease Control and and Prevention (CDC), (2014). "Mortality in the United States, NCHS Data Brief, No. 168, October. Retrieved 12/14,

5. Centers for Disease Control and and Prevention (CDC), (2014). "Mortality in the United States, NCHS Data Brief, No. 168, October. Retrieved 12/14,

6. Charles, W. (2008) Healthy Economy Requires Moral Restraints, Newsweek

7. Hobbs, M. (2002) Growing a Healthy Environment, Bulletin on Healthy Economy, New Zealand,

8. Mellisa, B. (2017) Fertility Law and Ethics, Fertility Today, USA.

9. Sheykhi, Mohammad T. (2001) Economic and Social Demography, 2nd Edition, Shekate Sahamie Enteshar, Tehran, Iran.

10. Sheykhi, Mohammad T. (2016) Sociology of Environment, Harir Publications, Tehran, Iran.

11. Stuart-Hamilton, Ian, The psychology of Ageing: An Introduction, London: Jessica Kingsly Publishers. ISBN 184310426-1.

12. Retrieved, 2019, Social Accounting.

13. Riley, M.W., Foner and J.Waring, (1988). "Sociology of Age." In N.J. Smelser, ed., Handbook of Sociology. Newbury Park, CA: Sage.

14. Ruhm, C. J. NBER, Working Paper, University of North Carolina, Bulletin on Aging and Health, Number 12102, 2006.

15. World Health Organization (WHO), (2014), "World Health Statistics, 2014." Retrieved 12/14

Ready to submit your research? Choose Auctores and benefit from:

* fast, convenient online submission

* rigorous peer review by experienced research in your field

* rapid publication on acceptance

* authors retain copyrights

* unique DOI for all articles

* immediate, unrestricted online access

At Auctores, research is always in progress.

Learn more www.auctoresonline.org/journals/neuroscienceand-neurological-surgery 